\title{
Electrochemical and Surface Characterization of a New Ti-Ta- Zr Alloy Covered with Biomimetic Bovine Serum Albumin
}

\author{
C. Vasilescu, S. I. Drob ${ }^{*}$, M. Popa, J. M. Calderon Moreno, M. Anastasescu, M. Marcu \\ Institute of Physical Chemistry "Ilie Murgulescu" of Romanian Academy, Spl. Independentei 202, \\ 060021, Bucharest, Romania \\ *E-mail: sidrob.icf@gmail.com
}

doi: $10.20964 / 2016.08 .31$

Received: 6 May 2016 / Accepted: 4 June 2016 / Published: 7 July 2016

\begin{abstract}
The surface of the new ternary Ti-15Ta-5Zr alloy was functionalized with bovine serum albumin (BSA) deposited by chemical method adapted to the composition of the alloy and its passive film. The BSA deposition was proved by atomic force microscopy (AFM), scanning electron microscopy (SEM) and Raman micro-spectroscopy techniques; also, its electrochemical behavior and corrosion resistance in physiological Ringer solution of different $\mathrm{pH}$ values (simulating the real functional conditions of an implant) were performed by cyclic potentiodynamic and linear polarization and electrochemical impedance spectroscopy (EIS). The BSA coating consists from cvasispherical aggregates (AFM) with high roughness which can promote the osteoblast cell development. SEM micrographs revealed a thick deposition with some porosity. EDX spectrum identified $\mathrm{C}$ and $\mathrm{N}$ elements from BSA and $\mathrm{Ca}$ and $\mathrm{P}$ from the deposition solution (Ringer) which can stimulate the bone formation. Raman spectra showed the similar composition of BSA powder and BSA deposited on the Ti-15Ta-5Zr alloy surface. Electrochemical parameters have more favorable values for the BSA coated alloy comparing with the bare alloy proving nobler electrochemical behavior, better passive ability of the BSA coated alloy. Corrosion parameters have superior values of about 3-10 times than those of the bare alloy, namely, the BSA coating is both protective and slightly porous permitting the interactions with the human biofluid. The impedance results were fitted with two time constants electric equivalent circuit for the bare alloy and with three time constants for the coated alloy.
\end{abstract}

Keywords: Biomimetic surface fuctionalization, AFM, SEM, EIS, Cyclic potentiodynamic and linear polarization

\section{FULLTEXT}

(C) 2016 The Authors. Published by ESG (www.electrochemsci.org). This article is an open access article distributed under the terms and conditions of the Creative Commons Attribution license (http://creativecommons.org/licenses/by/4.0/). 